San Jose State University

SJSU ScholarWorks

Master's Theses

Master's Theses and Graduate Research

Fall 2015

\title{
The Interactive Effect of Core Self-Evaluations and Perceived Organizational Support in Predicting Work Engagement
}

Martin Andres Araya

San Jose State University

Follow this and additional works at: https://scholarworks.sjsu.edu/etd_theses

\section{Recommended Citation}

Araya, Martin Andres, "The Interactive Effect of Core Self-Evaluations and Perceived Organizational Support in Predicting Work Engagement" (2015). Master's Theses. 4620.

DOI: https://doi.org/10.31979/etd.ja3w-4t9a

https://scholarworks.sjsu.edu/etd_theses/4620

This Thesis is brought to you for free and open access by the Master's Theses and Graduate Research at SJSU ScholarWorks. It has been accepted for inclusion in Master's Theses by an authorized administrator of SJSU ScholarWorks. For more information, please contact scholarworks@sjsu.edu. 
THE INTERACTIVE EFFECT OF CORE SELF-EVALUATIONS AND PERCEIVED ORGANIZATIONAL SUPPORT IN PREDICTING WORK ENGAGEMENT

\author{
A Thesis \\ Presented to \\ The Faculty of the Department of Psychology \\ San José State University \\ In Partial Fulfillment \\ of the Requirements for the Degree \\ Master of Science
}

by

Martin Araya

December 2015 
(C)2015

Martin Araya

ALL RIGHTS RESERVED 
The Designated Thesis Committee Approves the Thesis Titled

THE INTERACTIVE EFFECT OF CORE SELF-EVALUATIONS AND PERCEIVED ORGANIZATIONAL SUPPORT IN PREDICTING WORK ENGAGEMENT

by

Martin Araya

APPROVED FOR THE DEPARTMENT OF PSYCHOLOGY

SAN JOSÉ STATE UNIVERSITY

December 2015

Dr. Megumi Hosoda

Dr. Howard Tokunaga

Maria Inciong
Department of Psychology

Department of Psychology

Santa Clara County Office of Education 


\title{
ABSTRACT \\ THE INTERACTIVE EFFECT OF CORE SELF-EVALUATIONS AND PERCEIVED ORGANIZATIONAL SUPPORT IN PREDICTING WORK ENGAGEMENT
}

\author{
by Martin Araya
}

Given that work engagement has been shown to be related to positive individual and organizational outcomes, researchers have examined factors that predict work engagement. Personal resources and job resources are two factors that previous research has found to predict work engagement. The purpose of this study was to examine core self-evaluations (personal resource) and their interaction with perceived organizational support (job resource) on predicting working engagement. A total of 155 participants in a variety of job industries participated in an online survey. The study examined the direct effect of core self-evaluations in predicting work engagement as well as the interaction between core self-evaluations and perceived organizational support in predicting work engagement. In support of the first hypothesis, core self-evaluations were found to predict work engagement. However, no interaction effects of core self-evaluations and perceived organizational support in predicting work engagement were found. Perceived organizational support was found to strongly and directly predict work engagement above and beyond core self-evaluations. These findings suggest that in order to increase employee engagement, organizations should try to maximize core self-evaluations and perceived organizational support. Two ways that this can be achieved are through selection methods and providing mentors to new hires. 


\section{ACKNOWLEDGMENTS}

I would first like to thank my thesis chair Dr. Megumi Hosoda. Your seemingly infinite patience and ability to make me feel better about myself, even when I was at my lowest, has helped me immensely to get through this process. I would also like to thank Dr. Howard Tokunaga, your insight is second to none and my thesis is better for that. I would also like to thank Maria Inciong, without your support and encouragement I would probably still be working on this thesis.

Thank you to my friends and cohort. Special mention to Bonnie, I appreciate the help you have given me through this process.

Finally, I would like to thank my family. I love you all so much and I hope I have made you proud. 


\section{TABLE OF CONTENTS}

LIST OF TABLES

LIST OF FIGURES

INTRODUCTION

Definition of Work Engagement

Predictors of Work Engagement

Job resources $\ldots \ldots$

Personal resources $\ldots \ldots \ldots \ldots$

Relationship Between Core Self-Evaluations and Work Engagement...............8

Interaction of POS With Core Self-Evaluations _.......................................... 11

METHOD

Participants _._.

Procedures $\ldots \ldots \ldots$

Measures

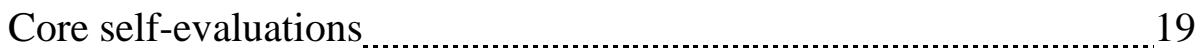

Perceived organizational support ........................................................ 20

Work engagement $\quad 20$

Demographic information $\ldots \ldots$

RESULTS $\ldots \ldots \ldots \ldots$

Descriptive Statistics

Pearson Correlations $\ldots \ldots \ldots \ldots$

Test of Hypotheses 
Additional Analyses: Dimensions of Work Engagement

DISCUSSION

Theoretical Implications

Practical Implications 30

Contributions of the Current Study. 31

Limitations and Directions for Future Research 31

Conclusion 32

REFERENCES 34 APPENDIX 37 


\section{LIST OF TABLES}

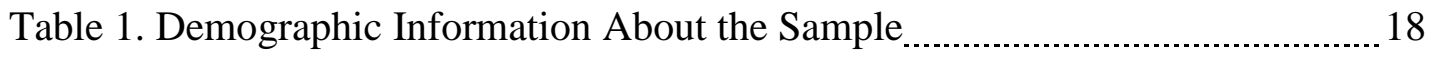

Table 2. Means, Standard Deviations, and Correlations $\ldots 21$

Table 3. Hierarchical Regression Analysis Summary for Variables Predicting Overall Work Engagement

Table 4. Means, Standard Deviations, and Correlations for Engagement

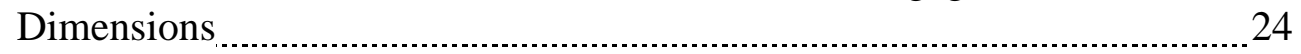

Table 5. Hierarchical Regression Analysis Summary for Variables Predicting Vigor 25

Table 6. Hierarchical Regression Analysis Summary for Variables Predicting Dedication 25

Table 7. Hierarchical Regression Analysis Summary for Variables Predicting Absorption 26 


\section{LIST OF FIGURES}

Figure 1. Proposed Interaction Between Core Self-Evaluations and POS in Predicting Work Engagement 


\section{Introduction}

For the majority of people, a great deal of their time each week is spent at work. Yet, many people seem to be dissatisfied with and disengaged from their jobs. To illustrate, according to a recent Gallup poll, only $13 \%$ of employees in the world are engaged at work, while $24 \%$ are actively disengaged (Crabtree, 2013). This is regrettable as work engagement has been found to have many positive outcomes for both companies and employees. For example, work engagement is associated with reduced turnover, increased productivity, increased profit, and higher customer satisfaction (Harter, Schmidt, \& Hayes, 2002). Additionally, work engagement benefits employees as it is associated with increased organizational commitment and worker health, and reduced worker exhaustion and turnover intention (Halbesleben, 2010).

Given the positive outcomes of work engagement, understanding factors that predict work engagement is an important step for organizations to improve levels of work engagement among their employees. For example, job resources have been found to predict work engagement (Ugwu, Onyishi, \& Rodríguez-Sánchez, 2014). Job resources

are defined as the physical, psychological, and social aspects of work that help employees achieve work goals, reduce demands of the job, and contribute to personal growth and development, and include feedback, autonomy, and role clarity (Bakker \& Demerouti, 2007).

Although researchers have studied job resources as predictors of work engagement, more recently they have also examined personal resources as predictors. Personal resources are defined as a positive evaluation of oneself regarding one's 
resiliency and a belief that one has control over the surrounding environment; examples of personal resources found to be positively related to work engagement include selfesteem, optimism, and self-efficacy (Salmela-Aro \& Nurmi, 2007; Xanthopoulou, Bakker, Demerouti, \& Schaufeli, 2009). These findings indicate that although organizations may provide job resources to their employees to increase work engagement, employees also possess personal resources that may influence their engagement in their work. Given that some personality traits predict work engagement, it is important to identify those individuals who are predisposed to be engaged in their work. Core self-evaluations are one such personality trait that constitutes an individual's evaluation of himself or herself and his or her control over their surroundings.

The present study proposes that core self-evaluations predict work engagement; furthermore, core self-evaluations and perceived organizational support (POS) interact in predicting work engagement. Core self-evaluations are defined as one's appraisal of his or her surroundings in relation to himself or herself and consist of self-esteem, neuroticism, locus of control, and self-efficacy (Erez \& Judge, 2001). Core selfevaluations have been found to have a positive relationship with motivation and performance (Erez \& Judge, 2001). Because work engagement can be looked at as a motivational concept (Rothbard, 2001), it is reasonable to believe core self-evaluations are positively related to work engagement. Although those with low core selfevaluations are expected to have lower levels of work engagement, screening and hiring only those who have high core self-evaluations is costly and unrealistic. Instead, creating a work environment in which employees feel supported and valued might help employees 
feel engaged with their work, especially those who have low core self-evaluations. Thus, POS might play an important interacting role with core self-evaluations in predicting work engagement.

POS is defined as employees' beliefs that their organization values their contributions and cares about their well-being (Eisenberger, Huntington, Hutchison, \& Sowa, 1986). A culture of support offered by an organization (e.g., training opportunities, health services, supervisor support) suggests that the organization cares about its employees. Therefore, it is argued that core self-evaluations and POS may interact in predicting work engagement such that employees with low core selfevaluations might benefit more from high POS than low POS.

The present study was designed to expand upon the sparse research regarding the relationship between core self-evaluations and work engagement, and also investigate the interaction between core self-evaluations and POS in predicting work engagement. The following sections discuss work engagement in more detail, review literature pertaining to the relationship between job resources (including core self-evaluations) and work engagement, and introduce POS as a job resource that interacts with core self-evaluations to predict work engagement.

\section{Definition of Work Engagement}

Schaufeli, Salanova, González-Romá, and Bakker (2002) defined work engagement as a work-related state of mind that is constituted of vigor, dedication, and absorption. Vigor is the willingness of employees to invest energy and effort into their work. Mental resilience and persistence through trying periods in the workplace also 
constitute vigor. Dedication refers to a sense of challenge, enthusiasm, significance, and pride in one's work. Schaufeli et al. note that dedication is similar to the notion of involvement, which is simply the psychological identification with one's work. However, dedication is particularly strong involvement and is much wider in scope. Absorption is characterized as being fully engrossed into one's work. Employees who are absorbed in their work have difficulties detaching themselves from what they are doing and have the perception that time passes quickly while performing their tasks.

Work engagement has been related to positive outcomes for organizations and employees. For instance, a meta-analysis by Halbesleben (2010) showed work engagement to be positively related to job performance, organizational commitment, employee health, and reduced turnover intentions. It has also been shown to be related to profitability, customer satisfaction, and profit (Harter et al., 2002). Work engagement has also been found to increase team performance as it can be considered the combined effort of engaged individual employees (Bakker \& Demerouti, 2008). Highly engaged employees can influence others, which in turn helps the team perform better as a whole. Work engagement has also been positively linked to organizational citizenship behavior (Kataria, Garg, \& Rastogi, 2013).

\section{Predictors of Work Engagement}

The studies discussed in the previous section demonstrate that work engagement not only positively affects employees, but also those around them, including co-workers, customers, and ultimately the company itself. Given the positive outcomes associated with work engagement, researchers have identified variables that predict work 
engagement. This study looked at two predictors of work engagement: job resources and personal resources. Both job and personal resources are tools employees use to cope with various stressors in the workplace. Core self-evaluations fall into the personal resources category as personal resources are what the employees bring with them to the job. POS is considered a job resource as it is a resource that is provided by the organization and can be used by an employee to cope with workplace stressors.

Job resources. Bakker and Demrouti (2007) developed the job demandsresources (JD-R) model to explain the relationship between job resources and work engagement. Job demands are aspects of a job that require psychological and/or physical costs; examples of job demands are project deadlines and long work hours. In contrast, job resources are physical, psychological, and social aspects of work that help employees reduce job demands, achieve work goals, and contribute to personal growth and development (Bakker \& Demerouti, 2007). Examples of job resources include autonomy in performing tasks, role clarity, positive relationships with supervisors, and opportunities for career advancement (Bakker \& Demerouti).

According to the job demands-resource (JD-R) model, job demands put strain on an employee which can have negative outcomes (e.g. burnout), whereas job resources help employees counteract job demands. One of the psychological processes within this model is that job resources lead to work engagement through both an intrinsic and extrinsic motivational role. Job resources foster employee's growth and fulfill basic human needs, thus playing an intrinsic role. Job resources also play an extrinsic motivational role because they are instrumental in achieving work goals. For example, 
giving more autonomy to employees fulfills their intrinsic motivation because employees feel competent and confident in their abilities, and also fulfills their extrinsic motivation because they can accomplish their tasks more effectively.

Researchers have found job resources to be positively related to work engagement. For example, Hultell and Gustavsson (2011) conducted a study and examined job resources and job demands in relation to work engagement. They measured 1,290 teachers a first time when they were finishing their education and a second time a year later when they had become employed. The job resources measured included autonomy, social support from supervisor, support from colleagues, active coping strategies, mastery of skills, and pay satisfaction. It was found that teachers who had more supervisor support, more skills to perform their job (i.e., mastery of skills), and more active coping strategies had higher work engagement.

In a similar study, Schaufeli, Bakker, and Van Rhenen (2009) conducted a longitudinal study in which they hypothesized that the amount of job resources present in an organization would predict telecommunication managers' engagement in their work. They examined social support, autonomy, opportunities to learn and develop, and feedback as the job resources. Schaufeli et al. measured job resources and work engagement twice, with one year separating the time of measurement. The initial measurement was used as a baseline to see if work engagement predicted future work engagement via an increase in job resources. Through the baseline analysis, they found that telecommunication managers who had more job resources available to them were more engaged in their work. They also found that high baseline levels of work 
engagement predicted an increase in job resources which in turn predicted more work engagement one year later.

Personal resources. More recently, researchers (e.g., Bakker \& Demerouti, 2007) have investigated personal resources as predictors of work engagement. As mentioned earlier, personal resources are defined as having a positive evaluation of oneself based on one's resiliency and belief that one has control over the surrounding environment (Xanthopoulou, Bakker, Demerouti, \& Schaufeli, 2009). Researchers have investigated personal resources in terms of personality traits (e.g., self-efficacy, selfesteem). Yet, research on the relationship between personal resources and work engagement is relatively scarce and the evidence that is available is not consistent. For example, examining the Big Five personality traits, Kim, Shin, and Swanger (2009) found that only neuroticism and conscientiousness predicted work engagement. In contrast, Woods and Sofat (2013) found a negative relationship between neuroticism and work engagement but did not find a relationship for conscientiousness. Furthermore, Karatepe and Olugbade (2009) examined relationships between personal resources and work engagement among hotel employees. They found that trait competitiveness and self-efficacy both had a positive relationship with work engagement, such that the more competitive and self-efficacious employees were, the more engaged they were in their work. In line with the studies demonstrating positive relationships between personal resources and work engagement, Halbesleben's (2010) meta-analysis found that selfefficacy and optimism were positively related to work engagement. These studies show that certain personality traits predict work engagement. 


\section{Relationship Between Core Self-Evaluations and Work Engagement}

As stated previously, core self-evaluations are hypothesized to predict work engagement. Core self-evaluations refer to one's fundamental appraisal of his or her surroundings (e.g. people or events) in relation to him or herself (Erez \& Judge, 2001). The core self-evaluations concept was proposed by Judge, Locke, and Durham (1997) in an effort to find a dispositional trait that predicted job satisfaction. Core self-evaluations are considered to be an aspect of personality and as such might be a personal resource.

Core self-evaluations are a fundamental higher-order trait, as they encompass specific evaluations such as self-esteem, self-efficacy, locus of control, and neuroticism. Self-esteem is the value one has on oneself as a human being. It is the basic appraisal one makes of oneself and is the most fundamental evaluation of the self (Judge, Locke, Durham, \& Kluger, 1998). Self-efficacy is defined as the degree to which an individual perceives his or her ability to meet demands and accomplish his or her tasks (Xanthopoulou et al., 2009). Locus of control refers to one's belief regarding how much control one has over one's life (Judge et al.). Finally, neuroticism is defined as having negative mentality and emotional instability for long periods of time. Those who are neurotic tend to turn to anger, anxiety, and depression more quickly than the average person. Individuals characterized as high on core self-evaluations display high levels of self-esteem and self-efficacy, internal locus of control, and low levels of neuroticism. Alternatively, individuals characterized as low on core self-evaluations display low levels of self-esteem and self-efficacy, and external locus of control, with moderate to high levels of neuroticism (Judge et al.). 
In the study conducted by Judge et al. (1997), self-esteem, self-efficacy, locus of control, and neuroticism were found to predict job satisfaction better together than when tested alone. Consequently, they proposed that these four traits could be explained by one broad underlying higher-order trait. What these four traits have in common is that they all involve evaluations of one's environment, which makes having the underlying fundamental core self-evaluations the basic appraisal of one's worthiness, effectiveness, and one's capabilities (Judge, Erez, Bono, \& Thoresen, 2003). Conceptually, selfesteem, locus of control, self-efficacy, and neuroticism can be seen as different ways in which core self-evaluations manifests itself. Since the Judge et al.'s (1997) study, core self-evaluations have been investigated in over 300 studies (PsycINFO search, April 20, 2015). Throughout these studies, core self-evaluations have been found to predict not only job satisfaction but other factors such as job burnout and life satisfaction (Zhou, Lu, Liu, Zhang, \& Chen, 2014; Jiang \& Jiang, 2015).

The hypothesis that core self-evaluations predict work engagement is consistent with the JD-R model because core self-evaluations serve as an intrinsic motivational role in employees' engagement in their work. For example, Rich, Lepine, and Crawford (2010) argued that the positive relationship between core self-evaluations and work engagement was due to individuals having confidence in their abilities and an internal locus of control, which lead them to be psychologically available to invest emotional, physical, and cognitive energy in their role performance. Core self-evaluations are also likely to serve as an extrinsic motivational role because those with high core selfevaluations can perform their jobs effectively and achieve their goals successfully. 
A few studies have examined the relationship between individual components of core self-evaluations and work engagement. For example, Xanthopoulou, Bakker, Demerouti, and Schaufeli (2009) studied the relationship between self-efficacy and work engagement among employees of an electrical engineering company. According to them, the positive relationship they found was probably due to an employees' belief that they could accomplish tasks, and thus they became more engaged as they knew what needed to be done. Self-esteem was also found to be positively related to work engagement in a 15-year longitudinal study of college students (Salmela-Aro \& Nurmi, 2007). Those who were found to have higher self-esteem in college were more engaged with their work 15 years later. As stated previously, Kim et. al. (2009) and Woods and Sofat (2013) found that neuroticism was negatively related to work engagement. Unfortunately, the locus of control and work engagement relationship has not been studied. However, it is expected there is a positive relationship between the two because if employees feel that work outcomes are contingent on their actions and not external events, then they are more likely to be engaged in their work as they feel their actions have a direct effect on company outcomes.

At present, the relationship between core self-evaluations and work engagement has been largely unexplored. Only a few studies have examined this relationship and showed that core self-evaluations were positively related to work engagement. For example, Lee (2013) found that core self-evaluations were positively related to work engagement among hotel employees and managers. Rich et al. (2010) also found a positive relationship between core self-evaluations and work engagement in a sample of 
firefighters and their supervisors. It should be noted that the main focus of these studies was not on the core-self evaluations and work engagement relationship and neither study conceptualized core self-evaluations as a personal resource, thus this study aimed to do both:

Hypothesis 1: Core self-evaluations will predict work engagement.

This study adds to the very sparse research on the core self-evaluations and work engagement relationship; however, just including these two variables may not be enough. Finding and hiring only employees who are high in core self-evaluations is ideal, but it is not always possible and realistic. Instead, it might be useful for organizations to determine whether factors within the organization may influence the relationship between employees' core self-evaluations and their engagement. This study examined the possible interacting effect of POS and core self-evaluations in predicting work engagement. POS is something an organization has control over as it is directly influenced by the organization's actions. By examining the interaction between core selfevaluations and POS, we address both internal factors (core self-evaluations) and environmental factors (POS).

\section{Interaction of POS With Core Self-Evaluations}

POS is defined as employees' beliefs that their organization values their contributions and cares about their well-being (Eisenberger et al.,1986). To this effect, POS serves an important role in an organization and has been linked to many positive outcomes. For example, POS has been found to be positively related to affective organizational commitment, job satisfaction, job performance, and negatively related to 
stress and turnover (Rhoades \& Eisenberger, 2002). This study proposes POS interacts with core self-evaluations in predicting work engagement.

Having high POS in an organization is important because employees may feel the need to reciprocate POS due to the norms of reciprocity (Rhodes \& Eisenberger, 2002). Employees may feel obligated to care more about their organization's objectives and be more invested in the organization's well-being by becoming more engaged in their work. POS also helps to meet the socio-emotional needs of employees. Socio-emotional needs constitute receiving emotional support, affiliation, self-esteem, and approval from others (Cohen \& Wills, 1985). POS indicates to employees that the organization views them as valuable employees and is proud of their accomplishments, is committed to them, and provides help and material aid to deal with stressful situations (Rhodes \& Eisenberger, 2002). Furthermore, POS increases employees' beliefs that their efforts on behalf of the organization will be recognized and rewarded (Eisenberger et al., 1986).

The conservation of resources (COR) model (Hobfoll, 1989) helps explain how POS and core self-evaluations interact to predict work engagement. This model suggests that employees strive to retain, protect, and build job and personal resources in order to reduce strains from job demands (Park, Jacob, Wagner, \& Baiden, 2014). It is expected that organizational support, being a job resource, interacts with core self-evaluations to predict work engagement. More specifically, low core self-evaluations employees are believed to demonstrate a strong positive relationship between POS and work engagement; on the other hand, high core self-evaluations employees are expected to show only a weak positive relationship between POS and work engagement. According 
to the COR model, low core self-evaluations employees would be expected to need more resources in order to be engaged in their work and POS is one such resource that can be accumulated, whereas those with high core self-evaluations already have the high levels of self-esteem, self-efficacy, and internal locus of control needed to fulfill socioemotional needs. Hobfoll notes that when a person develops resource surpluses, he or she is likely to experience positive well-being. This means that low core self-evaluations employees with high POS may experience a surplus of resources, allowing them to experience positive well-being which could lead to more positive outcomes like work engagement. POS gives those employees with low core self-evaluations a support structure where they feel that any stress or problem that arises can be tackled and solved with the help of the organization, which ultimately increases their level of engagement.

It is expected that one would find an interaction effect between core selfevaluations and POS in the research literature. Although there are no studies that have examined an interaction between core self-evaluations and POS in work engagement, there are a few studies that have demonstrated an interaction effect between core selfevaluations and POS for other job outcomes. For example, McNall, Masuda, Shanock, and Nicklin (2011) examined whether core self-evaluations interacted with POS in predicting work-to-family enrichment. Work-to-family enrichment occurs when "the experiences in one role improve the quality of life in the second role," (McNall et al., p. $139)$ and is seen as the positive side of work-family interface. Resources gained in the work role such as skills, perspectives, flexibility, or material resources are seen as producing positive affect in the work role such as enthusiasm, alertness, and high energy, 
which ultimately promotes increased performance in the home role. For example, flexibility may allow employees to play a better parenting role by allowing them to take care of their child at home if the child is not feeling well.

McNall et al. (2011) found that core self-evaluations and POS interacted to predict work-to-family enrichment such that the POS and work-to-family enrichment relationship was greater for those employees with low core self-evaluations than employees with high core self-evaluations. This means that the more employees perceived support from their organizations, the more work-to-family enrichment they experienced and this relationship was stronger for those with low core self-evaluations than those with high core self-evaluations. Furthermore, those employees with high core self-evaluations had high work-to-family enrichment regardless of whether POS was low or high.

Even though work-to-family enrichment and work engagement are two different concepts, there are similarities. Work engagement is similar to work-to-family enrichment in that it has similar positive affect in vigor, dedication, and absorption. Interaction effects of core self-evaluations and POS similar to the ones found in McNall et al. (2011) may be found in this current study because work-to-family enrichment and work engagement have the shared similarity of resources (i.e., enthusiasm and dedication).

Based on McNall's et al. (2011) study, it is then expected that POS and core selfevaluations interact in such a way that the POS and work engagement relationship will be greater for those employees with low core self-evaluations than employees with high core 
self-evaluations. Low core self-evaluations employees with high POS are expected to have high levels of work engagement and those employees low in core self-evaluations and low POS will be expected to have low levels of work engagement. This is due to high POS compensating for those with low core self-evaluations by fulfilling their socioemotional needs which is important for reducing job demands. In contrast, high core self-evaluations employees will be expected to have high work engagement when experiencing either low POS or high POS. Those with high core self-evaluations would feel little effects of POS due to their high core self-evaluations already fulfilling their socio-emotional needs which compensates for an unsupportive environment. Figure 1 demonstrates the hypothesized interaction.

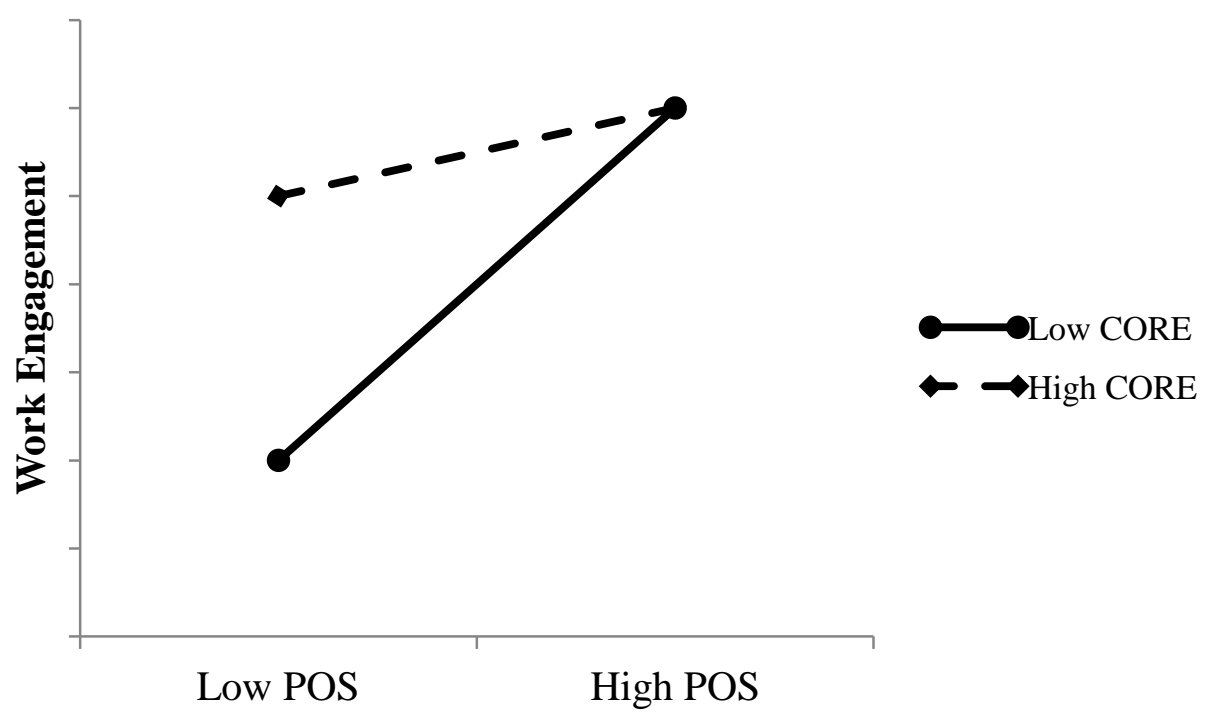

Figure 1: Proposed Interaction Between Core Self-Evaluations and POS in Predicting Work Engagement. 
Therefore:

Hypothesis 2: Core self-evaluations and POS will interact with one another in predicting work engagement such that the relationship between POS and work engagement relationship will be stronger for those with low core self-evaluations than for those with high core self-evaluations. 


\section{Method}

\section{Participants}

A total of 185 individuals participated in the study. Participants who indicated that they were not working at the time of data collection or had excessive missing data were excluded from further analyses; therefore, the final sample consisted of 155 participants. Table 1 displays demographic information of the participants. The sample consisted of $41.9 \%$ males $(n=65)$ and $56.8 \%$ females $(n=88)$ (two participants did not report their gender). Participant's ages ranged from 19 to 67 years with an average of 29.60 years $(\mathrm{SD}=10.33)$. The sample was ethnically diverse, with $46.5 \%$ of the participants identifying themselves as Asian, $21.9 \%$ as White, $18.7 \%$ as Hispanic, $1.9 \%$ as Black, .6\% as East Indian, and $9.7 \%$ as Other (one participant did not report ethnicity). Most participants worked part-time $(53.5 \%, n=83)$ and $50.3 \%(n=78)$ worked 30 or fewer hours a week. Participants worked in a variety of industries, including education, training, and library (31\%), sales and related (17.4\%), and business and financial operations $(11.6 \%)$. 
Table 1

Demographic Information About the Sample $(n=155)$

\begin{tabular}{lcc}
\hline Variables & $n$ & $\%$ \\
\hline Age & $M=29.6$ & $S D=10.33$
\end{tabular}

Gender

Male

Ethnicity

Asian

White

Hispanic

Black

East Indian

Other

Employment Status

Full-time

Part-time
Female

65

88

$41.9 \%$

$56.8 \%$

72

34

29

3

1

15

71

83

$45.8 \%$

$53.5 \%$

Average Hours Worked Per Week

Fewer than 20

$47 \quad 30.3 \%$

Between 20-30

31

44

33

$20.0 \%$

Between 31-40

More than 40 hours

$21.9 \%$

$18.7 \%$

$19.0 \%$

$0.6 \%$

$9.7 \%$

$28.4 \%$

$21.3 \%$
Occupation Type

Business and Financial Operations

Life, Physical, and Social Sciences

Community and Social Services

Healthcare

Sales and Related

Military/Protective Service

Architectural and Engineering

Legal

Education, Training, and Library

Food Preparation and Serving Related

Office and Administrative Support

\begin{tabular}{rr}
18 & $11.6 \%$ \\
2 & $1.3 \%$ \\
4 & $2.6 \%$ \\
11 & $7.1 \%$ \\
27 & $17.4 \%$ \\
2 & $1.3 \%$ \\
5 & $3.2 \%$ \\
6 & $3.9 \%$ \\
48 & $31.0 \%$ \\
18 & $11.6 \%$ \\
14 & $9.0 \%$ \\
\hline
\end{tabular}




\section{Procedures}

Data were collected using the Qualtrics ${ }^{\circledR}$ online survey system. The survey link was added into the SONA System ${ }^{\circledR}$ at the Business Department at San José State University. Business students who completed the survey received research credit that fulfilled their course requirements. The link and a short description of the study were also sent to the researcher's personal and professional contacts through email, text messaging, and social media. Recipients were encouraged to share the link with other contacts thus creating a snowball approach.

Participants who selected the linked survey were given a description of the study and an informed consent form. Those who clicked the "I AGREE" button were presented with survey items relating to core self-evaluations, work engagement, and POS. Participants who chose not to consent had the option to exit the survey by exiting the browser.

\section{Measures}

Unless otherwise indicated, the variables were measured using a 7-point Likert scale $(1=$ strongly disagree, $7=$ strongly agree $)$.

Core self-evaluations. Core self-evaluations were measured using the 12 -item core self-evaluations scale developed by Judge et al. (2003). Sample items include "I determine what will happen in my life" and "Sometimes I feel depressed." All items were summed and averaged, with higher scores indicating higher core self-evaluations. High core self-evaluations manifest themselves as a person with confidence in his or her 
abilities and the belief that he or she has control over his or her environment. Cronbach's alpha was .82 , indicating acceptable reliability.

Perceived organizational support. POS was measured using the short version of the POS scale originally designed by Eisenberger et al. (1986). The scale consisted of 16 items. Sample items include "The organization really cares about my well-being” and "If given the opportunity, the organization would take advantage of me." All items were summed and averaged. Higher scores indicate that a participant perceived his or her organization to be supportive. Higher POS means that the employee feels valued and feels like the organization cares about his or her wellbeing. Cronbach's alpha indicated high reliability of .93 .

Work engagement. Work engagement was measured by using the 9-item Utrecht Work Engagement scale. Sample items include "My job inspires me" and "At my job, I feel strong and vigorous.” Higher scores indicate higher degrees of work engagement. Higher degrees of work engagement mean employees spend more of their time focused on their tasks, are more willing to stay overtime, are happier than others to be at work, show pride in what they do, and find themselves engrossed in their work. Cronbach's alpha was .92 , which indicates high reliability.

Demographic information. Participants were asked to answer various demographic information questions including age, sex, ethnicity, work time status (fulltime or part-time), average hours worked per week, and current job type (e.g. Architectural and Engineering, Military/Protective Service, Business and Financial Operations). 


\section{Results}

\section{Descriptive Statistics}

Table 2 shows the means, standard deviations, and correlations among the measured variables. Participants reported relatively high levels of core-self evaluations $(M=4.93, S D=.83)$ and work engagement $(M=4.99, S D=1.12)$. Furthermore participants perceived that their organizations supported them $(M=4.82, S D=1.05)$.

Table 2

Means, Standard Deviations, and Correlations $(n=155)$

\begin{tabular}{lccccc}
\hline Variable & Mean & SD & 1 & 2 & 3 \\
\hline 1. Core Self-Evaluations & 4.93 & 0.83 & $(.82)$ & & \\
2. Perceived Organizational Support & 4.82 & 1.05 & .07 & $(.93)$ & \\
3. Work Engagement & 4.99 & 1.12 & $.23 * *$ & $.60 * * *$ & $(.92)$ \\
\hline
\end{tabular}

Notes. $* p<.05 ; * * p<.01 ; * * * p<.001$

Reliability coefficients (Cronbach's Alpha) are presented on the diagonal.

\section{Pearson Correlations}

As can be seen in Table 2, core self-evaluations were positively related to work engagement $(r=.23, p<.01)$, indicating that the higher the core self-evaluations of individuals, the more engaged they were. There was no statistically significant relationship between core self-evaluations and POS $(r=.07, p=.36)$. POS was positively and strongly related to work engagement $(r=.60, p<.001)$, which demonstrates that participants who felt that their organizations were highly supportive and cared about them were more likely to be engaged in their work.

\section{Test of Hypotheses}

A hierarchical regression analysis was used to test Hypothesis 1 that core selfevaluations would predict work engagement and Hypothesis 2 that POS and core self- 
evaluations would interact to predict work engagement. In the analysis, core selfevaluations were entered in Step 1, POS was entered in Step 2, and finally the cross product of core self-evaluations and POS as an interaction term was entered in Step 3. If the variance explained by the interaction between core self-evaluations and POS is statistically significant, this would indicate a significant interaction effect.

The results of the hierarchical regression analysis are shown in Table 3. The results of Step 1 showed that core self-evaluations were indeed a significant predictor of work engagement and explained $6 \%$ of the variance in work engagement, $R^{2}=.06, R^{2}$ adj $=.05, F(1,153)=8.87, p=.003$; this result supports Hypothesis 1 . Results of Step 2 showed that POS accounted for an additional $34 \%$ of the variance in work engagement above and beyond the variance explained by core self-evaluations, $\Delta R^{2}=.34, \Delta F(1,152)$ $=87.61, p<.001$. Overall, these results showed that core self-evaluations and POS independently predicted work engagement, with a large incremental effect of POS above and beyond the variance explained by core self-evaluations. The results of Step 3 demonstrated that the interaction term of core self-evaluations and POS did not explain a significant amount of variance above and beyond their individual effects, $\Delta R^{2}=.00$, $\Delta F(1,151)=.185, p=.67$. These results show that core self-evaluations and POS did not interact with each other to predict work engagement. Thus, Hypothesis 2 was not supported. 
Table 3

Hierarchical Regression Analysis Summary for Variables Predicting Overall Work Engagement

\begin{tabular}{llll}
\hline Steps and Predictor Variables & $\mathrm{R}^{2}$ & $\Delta \mathrm{R}^{2}$ & $\beta$ \\
\hline Step 1: & & & $.06^{* *}$ \\
$\begin{array}{l}\text { Core Self-Evaluations (CORE) } \\
\text { Step 2: }\end{array}$ & $.06^{* *}$ & & $.23^{* *}$ \\
$\begin{array}{l}\text { Perceived Organizational Support (POS) } \\
\text { Step 3: }\end{array}$ & $.40^{* * *}$ & $.34^{* * *}$ & $.59^{* * *}$ \\
CORE*POS & .40 & & .00 \\
\hline
\end{tabular}

Notes. $* p<.05 ; * * p<.01 ; * * * p<.001$

\section{Additional Analyses: Dimensions of Engagement}

Additional analyses were conducted to see if POS interacted with core self-

evaluations in predicting the individual dimensions of work engagement (vigor,

dedication, and absorption). Previous research has looked at each dimension of engagement individually and some differences between dimensions have been found.

For example, self-efficacy has been found to be more related to vigor and dedication than to absorption (Halbesleben, 2010).

Means, standard deviations, and correlations can be found in Table 4. Core selfevaluations had significant correlations with vigor $(r=.27, p<.01)$ and dedication $(r=$ $.21, p<.01)$, but not with absorption $(r=.15, p=.06)$. This finding means that participants who demonstrated higher core-self evaluations felt more vigorous during work and were more dedicated to their jobs, but were not necessarily more absorbed in their work. In contrast, POS was found to be similarly and positively correlated with vigor $(r=.54, p<.001)$, dedication $(r=.57, p<.001)$, and absorption $(r=.54, p<.001)$. 
Table 4

Means, Standard Deviations, and Correlations for Engagement Dimensions $(n=155)$

\begin{tabular}{lccccccc}
\hline Variable & Mean & SD & 1 & 2 & 3 & 4 & 5 \\
\hline 1. Core Self-Evaluations & 4.93 & 0.83 & $(.82)$ & & & & \\
2. Perceived Organizational Support & 4.82 & 1.05 & .07 & $(.93)$ & & & \\
3. Vigor & 4.66 & 1.23 & $.27 * *$ & $.54 * * *$ & $(.83)$ & & \\
4. Dedication & 5.27 & 1.28 & $.21 * *$ & $.57 * * *$ & $.82^{* * *}$ & $(.88)$ & \\
5. Absorption & 5.07 & 1.18 & .15 & $.54 * * *$ & $.62 * * *$ & $.76^{* * *}$ & $(.77)$ \\
\hline
\end{tabular}

Notes. $* p<.05 ; * * p<.01 ; * * * p<.001$

Reliability coefficients (Cronbach's Alpha) are presented on the diagonal.

The first model analyzed vigor as a dependent variable. The results are presented in Table 5. As in the previous hierarchical regression analysis, Step 1 started with entering core self-evaluations followed by POS in Step 2, and finally the cross product of core self-evaluations and POS as an interaction term was entered as Step 3. Core selfevaluations were found to be a significant predictor of vigor and explained $7 \%$ of variance, $R^{2}=.07, R^{2}$ adj $=.07, F(1,153)=12.15, p=.001$. This means that high core self-evaluation predicted feeling vigorous and energetic during work. In Step 2, POS accounted for an additional $27 \%$ of variance in vigor, $\Delta R^{2}=.27, \Delta F(1,152)=61.94, \mathrm{p}<$ .001. As with overall work engagement, the interaction term of core self-evaluations and POS in Step 3 did not account for any significant portion of the variance above and beyond what was already accounted for by core self-evaluations and POS, $\Delta R^{2}=.00$, $\Delta F(1,151)=.480, p=.49$. Core self-evaluations and POS did not interact with one another to predict vigor. 
Table 5

Hierarchical Regression Analysis Summary for Variables Predicting Vigor

\begin{tabular}{llll}
\hline Steps and Predictor Variables & $\mathrm{R}^{2}$ & $\Delta \mathrm{R}^{2}$ & $\beta$ \\
\hline Step 1: & & & $27 * *$ \\
Core Self-Evaluations & $.07 * *$ & $.07 * *$ & \\
$\begin{array}{l}\text { Step 2: } \\
\text { Perceived Organizational Support }\end{array}$ & $.34 * * *$ & $.27 * * *$ & $.52 * * *$ \\
Step 3: & & & .34 \\
CORE*POS & .34 & .00 & \\
\hline Notes. $* p<.05 ; * * p<.01 ; * * * p<.001$ & &
\end{tabular}

The second model analyzed dedication as a dependent variable. Results are presented in Table 6. In Step 1, core self-evaluations were entered, followed by POS in Step 2, and finally in Step 3, the interaction term between them was entered. Core selfevaluations was found to be a significant predictor of dedication and explained $4 \%$ of variance, $R^{2}=.04, R^{2} \mathrm{adj}=.04, F(1,153)=7.07, \mathrm{p}<.01$. In Step 2, POS accounted for an additional $31 \%$ of variance in vigor, $\Delta R^{2}=.31, \Delta F(1,152)=71.82, p<.001$. In Step 3 , the interaction term did not account for any significant portion of the variance above and beyond core self-evaluations and POS, $\Delta R^{2}=.00, \Delta F(1,151)=.005, p=.95$. Core selfevaluations and POS did not interact in predicting dedication.

Table 6

Hierarchical Regression Analysis Summary for Variables Predicting Dedication

\begin{tabular}{llll}
\hline Steps and Predictor Variables & $\mathrm{R}^{2}$ & $\Delta \mathrm{R}^{2}$ & $\beta$ \\
\hline $\begin{array}{l}\text { Step 1: } \\
\text { Core Self-Evaluations }\end{array}$ & $.04 * *$ & $.04 * *$ & $.21^{* *}$ \\
$\begin{array}{l}\text { Step 2: } \\
\text { Perceived Organizational Support }\end{array}$ & $.35^{* * *}$ & $.31^{* * *}$ & $.56^{* * *}$ \\
Step 3: & & & \\
CORE*POS & .35 & .00 & .03 \\
\hline Notes. *p<.05;**p<.01;***p<.001 & & &
\end{tabular}


Table 7 shows the final model which examined absorption as a dependent variable. As in the previous two analyses, Step 1 consisted of entering core selfevaluations, POS in Step 2, and the interaction term in Step 3. Unlike in the previous analyses, core self-evaluations were not a significant predictor of absorption, $R^{2}=.02$, $R^{2} \mathrm{adj}=.02, F(1,153)=3.43, p=.066$. POS was found to significantly predict absorption and accounted for an additional $28 \%$ of variance, $\Delta R^{2}=.28, \Delta F(1,152)=61.50, p<.001$. As with the other models, the interaction term in Step 3 did not account for any significant portion of the variance above and beyond what was already accounted for by core self-evaluations and POS, $\Delta R^{2}=.00, \Delta F(1,151)=.134, p=.715$. These results showed that core self-evaluations and POS did not interact with one another in predicting absorption.

Table 7

Hierarchical Regression Analysis Summary for Variables Predicting Absorption

\begin{tabular}{llll}
\hline Steps and Predictor Variables & $\mathrm{R}^{2}$ & $\Delta \mathrm{R}^{2}$ & $\beta$ \\
\hline Step 1: & & & .15 \\
Core Self-Evaluations & .02 & .02 & $.53^{* * *}$ \\
$\begin{array}{l}\text { Step 2: } \\
\text { Perceived Organizational Support }\end{array}$ & $.30^{* * * *}$ & $.28^{* * *}$ & \\
$\begin{array}{l}\text { Step 3: } \\
\text { CORE*POS }\end{array}$ & .30 & & .18 \\
\hline
\end{tabular}

Notes. $* p<.05 ; * * p<.01 ; * * * p<.001$ 


\section{Discussion}

Work engagement has been linked to many positive individual (e.g. performance, organizational commitment, employee health) and organizational (e.g. reduced turnover, better team performance) outcomes; however, only $13 \%$ of employees have been estimated to be engaged in their work (Crabtree, 2013). Because of the positive outcomes associated with work engagement, a considerable amount of attention has been paid to examine variables that predict work engagement. Yet, the majority of studies have focused on job resources as predictors of work engagement, with little attention paid to personal resources as predictors. This study aimed to examine core self-evaluations as a personal resource and the interaction between core self-evaluations and POS in predicting work engagement.

Hypothesis 1 stated that core self-evaluations would predict work engagement. Consistent with the hypothesis, core self-evaluations positively predicted work engagement. Those employees with higher core self-evaluations were more engaged in their work. This finding indicates that some personality traits have a role to play in deciding how engaged someone would be in the workplace and suggest that in predicting work engagement, it is not enough to just look at job resources but also it is necessary to take into account what the individual brings to the workplace.

Hypothesis 2 stated that core self-evaluations and POS would interact in predicting work engagement such that the relationship between POS and work engagement would be stronger for those with low core self-evaluations than those with high core self-evaluations. Results showed that although POS predicted work 
engagement above and beyond the effect of core self-evaluations, there was no interaction effect between core self-evaluations and POS. Therefore, this hypothesis was not supported.

A possible explanation for the lack of the interaction between core selfevaluations and POS could be that employees with low core-self evaluations have a mistrust of the motives of the organization. Those with low core self-evaluations are characterized as having high levels of neuroticism and low levels of self-efficacy, and thus, they may see their organization in a negative light even though an organization is indeed supportive. Furthermore, those with low core self-evaluations might see a more sinister motive behind an organization's supportive attempts or feel that the organization is not capable of helping them. However, this interpretation is only speculative. Another possible explanation is that, given the result that POS explained a much larger proportion of the variance in work engagement, POS might exert only a direct influence on work engagement. This means that POS is an important job resource in predicting work engagement. This idea is consistent with other studies (Gillet, Huart; Colombat, Fouquereau, 2013) that found that POS predicted work engagement.

\section{Theoretical Implications}

The results of the present study demonstrate that core self-evaluations serve as an important personal resource that predicts work engagement. This finding is in line with previous research and helps to add to the very sparse literature of the core selfevaluations and work engagement relationship. Furthermore, POS was found to directly predict work engagement above and beyond core self-evaluations, indicating its value as 
an important job resource. Both core self-evaluations and POS should be viewed as important resources utilized by employees in producing positive work outcomes. By looking at these variables as resources, we see both POS and core self-evaluations as important variables that demonstrate positive effects in the workplace. The findings of this study also support the tenets of JD-R model in that a personal resource predicted a positive outcome, in this case work engagement.

Unfortunately, this study did not find an interaction effect between core selfevaluations and POS in predicting work engagement. Given that McNall et al. (2011) did find an interaction between core self-evaluations and POS in predicting work-to-family enrichment, the lack of interaction effect in this study has some theoretical implications. There may be some hidden confounding variable that influences the interaction effect between core self-evaluations and POS. An explanation for the lack of the interaction effect is that the dependent variable may determine whether core self-evaluations and POS interact. McNall et al. (2011) described their dependent variable (work-to-family enrichment) as "the extent to which experiences in one role improve the quality of life in the other role.” (p. 134). Work-to-family enrichment focuses on resource gains from either the job or home role which promotes higher performance in the other role. This makes work-to-family enrichment different from work engagement because work engagement does not focus on an individual's roles (job or home roles). Work engagement is examining an employee's state of mind in the work role and could be the explanation for why McNall et al. and this study had different results. This is something 
future research can expand upon by looking at various work outcomes and see which ones interact and why there is an interaction in one outcome but not others.

\section{Practical Implications}

The results of this study that both core self-evaluations and POS played important roles in predicting employee's work engagement offer several practical implications. Given the importance of work engagement as a positive work outcome, organizations should try to maximize core self-evaluations and POS in their employees. One way to accomplish this is through selection. That is, companies may use a selection test to help identify and hire those who have high core self-evaluations. Companies are likely to benefit from hiring such individuals because core self-evaluations are not only positively related to work engagement, but also other positive outcomes such as job satisfaction and job performance (Erez \& Judge, 2001; Jiang \& Jiang, 2015; Zhou et al., 2014).

Another practical implication of the results is to make sure that employees see their organization as supportive and that the organization has a vested interest in their well-being. Developing trust, sharing and being open with information whether good or bad, and allowing access to opportunities for employees to learn and develop are things organizations can do that have been found to predict POS (Ghani \& Hussin, 2009). For example, providing mentors to those new and less experienced employees in the company so that they can learn new things and develop skills is just one way of achieving higher levels of POS in an organization. 


\section{Contributions of the Current Study}

This study has several strengths that contribute to the overall body of knowledge for work engagement. First, unlike previous studies on the core self-evaluations and work engagement relationship, this study's sample was ethnically diverse, had people of various ages, and different jobs. Having a diverse sample is important because a homogeneous sample might limit this study's findings to only a specific population. By having this diverse sample, it is less likely that the current findings are due to age, job type, or ethnicity of participants.

Another contribution of this study is that it examined core self-evaluations and POS as a resource that could directly influence as well as interact with one another to influence work engagement. This is important because looking at each variable as a resource opens up the idea that core self-evaluations and POS can play a role in alleviating job demands and promote positive work outcomes.

\section{Limitations and Directions for Future Research}

Despite the strengths of this study, there are still some limitations. One such limitation is that the data were collected in the United States. This means that the sample were all Americans and thus, the findings are probably reflective of an individualistic culture. This means that the findings may not apply to any collectivistic cultures such as China or Japan. Future research may want to replicate this study but take into account various cultures and countries not sampled in this study. Another limitation of this study is that half the sample size consisted of participants with part-time jobs which may have affected the results. Future research may want to just look at only full-time employees as 
they invest more time at work and may take their jobs more seriously than part-time employees.

Future research may also want to look at other job resources in predicting work engagement as personal resources are only half of the equation when it comes to work engagement and it is important to examine what variables interact with one another. For example, core self-evaluations and autonomy may interact in predicting work engagement because autonomy would be expected to influence low core self and high core self individuals differently. An expected finding would probably be that the relationship between autonomy and work engagement will be stronger for those with high core self-evaluations than those with low core self-evaluations because those with low self core-evaluations are not confident in doing things on their own.

Lastly, this is a cross-sectional study and no causal statement can be made. This is due to the fact that a cross-sectional study only gathers data from one moment in time whereas with longitudinal studies it allows for comparisons of data through multiple instances in a person's life where moods, attitudes, cognitive processes, and personality can change (Spector, 1994). Even though longitudinal studies cannot control for all variables, it is much better in making causal statements (Spector), thus future research should utilize a longitudinal design.

\section{Conclusion}

Work engagement is an important variable that pertains to almost everyone working today. Consistent with the hypothesis, this study demonstrated that core selfevaluations predicted work engagement. Although this study did not find an interaction 
effect between core self-evaluations and POS in predicting work engagement, POS directly impacted work engagement. Thus, this study also sheds light on the predictive power of POS on work engagement. These findings have important theoretical and practical implications because not only do they contribute to the literature, but they also demonstrate how both core self-evaluations and POS are important pieces of the work engagement puzzle and that companies should look at both variables if they want to have a more engaged workforce. 


\section{References}

Bakker, A. B., \& Demerouti, E. (2007). The Job Demands-Resources model: State of the art. Journal of Managerial Psychology, 22, 309-328.

Bakker, A. B., \& Demerouti, E. (2008). Towards a model of work engagement. The Career Development International, 13, 209-223.

Cohen, S., \& Wills, T.A. ( 1985). Stress, social support and the buffering hypothesis. Psychological Bulletin, 98, 310-357.

Crabtree, S. (2013, October 3). Worldwide, 13\% of employees are engaged at work. Gallup. Retrieved from http://www.gallup.com

Eisenberger, R., Huntington, R., Hutchison, S., \& Sowa, D. (1986). Perceived organizational support. Journal of Applied Psychology, 71, 500-507.

Erez, A., \& Judge, T. A. (2001). Relationship of core self-evaluations to goal setting, motivation, and performance. Journal of Applied Psychology, 86, 1270-1279.

Ghani, N. \& Hussin, T., (2009). Antecedents of perceived organizational support. Canadian Social Science, 5, 121-130.

Gillet, N., Huart, I., Colombat, P., \& Fouquereau, E. (2013). Perceived organizational support, motivation, and engagement among police officers. Professional Psychology: Research and Practice, 44, 46-55.

Halbesleben, J. B. (2010). A meta-analysis of work engagement: Relationships with burnout, demands, resources, and consequences. In A. B. Bakker (Ed.), Work Engagement: A Handbook of Essential Theory and Research (pp. 102-117). New York, NY US: Psychology Press.

Harter, J. K., Schmidt, F. L., \& Hayes, T. L. (2002). Business-unit-level relationship between employee satisfaction, employee engagement, and business outcomes: A meta-analysis. Journal of Applied Psychology, 87, 268-279.

Hobfoll, S. E. (1989). Conservation of resources: A new attempt at conceptualizing stress. American Psychologist, 44, 513-524.

Hultell, D., \& Gustavsson, J. (2011). Factors affecting burnout and work engagement in teachers when entering employment. Work: Journal of Prevention, Assessment \& Rehabilitation, 40, 85-98. 
Jiang, Z., \& Jiang, X. (2015). Core self-evaluation and life satisfaction: The personenvironment fit perspective. Personality and Individual Differences, 7568-73.

Judge, T. A., Locke, E. A., \& Durham, C. C. (1997). The dispositional causes of job satisfaction: A core evaluations approach. Research in Organizational Behavior, 19, 151-188.

Judge, T. A., Locke, E. A., Durham, C. C., \& Kluger, A. N. (1998). Dispositional effects on job and life satisfaction: The role of core evaluations. Journal of Applied Psychology, 83, 17-34.

Judge, T. A., Erez, A., Bono, J. E., \& Thoresen, C. J. (2003). The core self-evaluations scale: Development of a measure. Personnel Psychology, 56, 303-331.

Karatepe, O. M., \& Olugbade, O. A. (2009). The effects of job and personal resources on hotel employees' work engagement. International Journal of Hospitality Management, 28, 504-512.

Kataria, A., Garg, P., \& Rastogi, R. (2013). Does psychological climate augment OCBs? The mediating role of work engagement. The Psychologist-Manager Journal, 16, 217-242.

Kim, H., Shin, K., \& Swanger, N. (2009). Burnout and engagement: A comparative analysis using the big five personality dimensions. International Journal of Hospitality Management, 28, 96-104.

Lee, J. (2013). Antecedents and consequences of employee engagement: Empirical study of hotel employees and managers. Dissertation Abstracts International Section A, 73.

McNall, L. A., Masuda, A. D., Shanock, L., \& Nicklin, J. M. (2011). Interaction of core self-evaluations and perceived organizational support on work-to-family enrichment. Journal of Psychology, 145, 133-149.

Park, H. I., Jacob, A. C., Wagner, S. H., \& Baiden, M. (2014). Job control and burnout: A meta-analytic test of the conservation of resources model. Applied Psychology: An International Review, 63, 607-642.

Rhoades, L., \& Eisenberger, R. (2002). Perceived organizational support: A review of the literature. Journal of Applied Psychology, 87, 698-714. 
Rich, B., Lepine, J. A., \& Crawford, E. R. (2010). Job engagement: Antecedents and effects on job performance. Academy of Management Journal, 53, 617-635.

Rothbard, N. P. (2001). Enriching or depleting? The dynamics of engagement in work and family roles. Administrative Science Quarterly, 46, 655-684.

Salmela-Aro, K., \& Nurmi, J. (2007). Self-esteem during university studies predicts career characteristics 10 years later. Journal of Vocational Behavior, 70, 463-477.

Schaufeli, W. B., Salanova, M., González-Romá, V., \& Bakker, A. B. (2002). The measurement of engagement and burnout: A two sample confirmatory factor analytic approach. Journal of Happiness Studies, 3, 71-92.

Schaufeli, W. B., Bakker, A. B., \& Van Rhenen, W. (2009). How changes in job demands and resources predict burnout, work engagement, and sickness absenteeism. Journal of Organizational Behavior, 30, 893-917.

Spector, P. (1994). Using self-report questionnaires in OB research: A comment on the use of a controversial method. Journal of Organizational Behavior, 15, 385-392.

Ugwu, F. O., Onyishi, I. E., \& Rodríguez-Sánchez, A. M. (2014). Linking organizational trust with employee engagement: The role of psychological empowerment.

Personnel Review, 43, 377-400.

Woods, S. A., \& Sofat, J. A. (2013). Personality and engagement at work: The mediating role of psychological meaningfulness. Journal of Applied Social Psychology, 43, 2203-2210.

Xanthopoulou, D., Bakker, A. B., Demerouti, E., \& Schaufeli, W. B. (2009). Reciprocal relationships between job resources, personal resources, and work engagement. Journal of Vocational Behavior, 74, 235-244.

Zhou, Y., Lu, J., Liu, X., Zhang, P., \& Chen, W. (2014). Effects of core self-evaluations on the job burnout of nurses: The mediator of organizational commitment. Plos ONE, 9 . 


\section{Appendix}

Survey Items

The Core Self-Evaluations Scale: Development of a Measure (Judge, Erez, Bono, \&

Thoresen, 2003)

1. I am confident 1 get the success I deserve in life.

2. Sometimes I feel depressed, (r)

3. When I try, I generally succeed.

4. Sometimes when I fail I feel worthless, (r)

5. I complete tasks successfully.

6. Sometimes, I do not feel in control of my work, (r)

7. Overall, I am satisfied with myself.

8. I am filled with doubts about my competence, (r)

9. I determine what will happen in my life.

10. I do not feel in control of my success in my career, (r)

11. I am capable of coping with most of my problems.

12. There are times when things look pretty bleak and hopeless to me. (r)

Perceived Organizational Support (Eisenberger, Huntington, Hutchison, \& Sowa, 1986)

1. The organization values my contribution to its well-being.

2. If the organization could hire someone to replace me at a lower salary it would do so.

(R)

3. The organization fails to appreciate any extra effort from me. (R)

4. The organization strongly considers my goals and values.

5. The organization would ignore any complaint from me. (R)

6. The organization disregards my best interests when it makes decisions that affect me.

(R)

7. Help is available from the organization when I have a problem.

8. The organization really cares about my well-being.

9. Even if I did the best job possible, the organization would fail to notice. (R)

10. The organization is willing to help me when I need a special favor.

11. The organization cares about my general satisfaction at work.

12. If given the opportunity, the organization would take advantage of me. (R)

13. The organization shows very little concern for me. (R)

14. The organization cares about my opinions.

15. The organization takes pride in my accomplishments at work.

16. The organization tries to make my job as interesting as possible.

Work and Well-being Survey (Utrecht Work Engagement Scale)

1. At my work, I feel bursting with energy

2. At my job, I feel strong and vigorous

3. I am enthusiastic about my job

4. My job inspires me 
5. When I get up in the morning, I feel like going to work

6. I feel happy when I am working intensely

7. I am proud of the work that I do

8. I am immersed in my work

9. I get carried away when I'm working

Demographics

1. What is your sex? Male Female

2. What is your ethnicity?

$\begin{array}{lll}\text { White } & \text { Black } & \text { Hispanic } \\ \text { Asian } & \text { East Indian } & \text { Other }\end{array}$

3. Age? years old

4. Do you work: Part time Full time

5. On average, I work

Fewer than 20 hours a week Between 31-40 hours a week

Between 20-30 hours per week More than 40 hours per week

6. What is your current job? If you have more than one job, please select the job in which you work the most hours.

Business and Financial Operations Life, Physical, and Social Sciences Architectural and Engineering Community and Social Services Legal

Healthcare

Sales and Related

Military/Protective Service
Education, Training, and Library

Food Preparation and Serving Related Office and Administrative Support 